\title{
A Study on Chinglish in College English Scientific Journals of China
}

\author{
Zhang Xie, Ji Huanqi \\ College of Literature and Law, Sichuan Agricultural University, Ya'an 625014, China
}

Keywords: Chinglish; College English scientific journal of China; corpus data; suggestion

\begin{abstract}
Owing to the influences of Chinese thinking pattern and expressing conventions, Chinglish can widely be found in the college English scientific journals in China and greatly hinders Chinese scholars from showing the domestic scientific and technological achievements and engaging in international academic exchanges. Through constructing a mini corpus data of English theses and retrieval software, this paper analyzes the features of Chinglish at lexical and syntactical levels and thus advances suggestions on eliminating Chinglish from the perspective of English competence, editing and contribution.
\end{abstract}

\section{Introduction}

As China's opening up to the world reaches a brand new stage, China's communication with the international community becomes even wider and consequently more and more people use English for different purposes. However, there is always a barrier that has been confusing the Chinese ever since they began to get involved in cross-cultural communication toward the end of Ming Dynasty. Such barrier manifests itself frequently when Chinese people speak English, write English or translate Chinese into English. Many English discourses produced by the Chinese form a special type of English variety which is now commonly known as Chinglish. The study of Chinglish has been going on over 70 years since M. S. Serjeantson first introduced such a term in his book titled A History of Foreign Words in English in 1935. Researches about Chinglish in China can be dated back to 1980s and they mainly approached Chinglish from the perspective of college English writing, English for tourism, news English, English for current affairs, English for public signs and Translation from Chinese into English, etc. This paper intends to take a new approach toward Chinglish by examining the college English scientific journals issued in China. 100 theses are sampled from over 20 universities enlisted in national "985 Project", which usually represent the first rate universities in China. Those theses are utilized to construct a mini corpus data which are examined by MicroConcord, a type of information retrieval software developed by Oxford University, to analyze the features of Chinglish in them and counter measures to remove Chinglish are proposed accordingly.

\section{Chinglish and Its Causes}

Chinglish is generally regarded as a kind of interlanguage developed by the English learners whose native language is Chinese. Chinglish is thus neither Chinese nor English, but is a malformed type of English owing to the influences of Chinese language and culture. Such kind of phenomenon is usually caused by mother tongue transfer, which is defined by Odlin (1989) as the process of using knowledge of the first language in learning a second language. There are positive transfer and negative transfer. Positive transfer occurs when the first language knowledge benefits the use of target language but when the former interferes the latter negative transfer comes into being. Therefore, negative transfer is also termed as interference. In other words, positive transfer indicates that mother tongue facilitates the learning of the target language while negative transfer is debilitative, thus hindering the target language learning.

Chinglish is apparently caused by negative transfer. Li Wenzhong (1993) defined Chinglish as the ill-formed English which fails to comply with the standard English rules or conventions of the English culture owing to the interference of Chinese and is usually incomprehensible or unacceptable in the eyes of the English native speakers. It is because such interference makes 
Chinese English learners and users mechanically apply Chinese rules to the target language context. Li's definition about Chinglish has been widely acknowledged and scholars in China discussed the causes of Chinglish from different perspectives. Zhuang Jiangzhuan (2000) believed that there are two major factors that cause Chinglish: one is the failure to comprehend the Chinese discourse and the other is the inability to get oneself familiarized with the English language features. Wang Nongsheng (2000) probed the causes from four aspects, namely, wrong collocation, overuse of modifiers, overuse of personification in Chinese and the emergence of too many new expressions with Chinese Characteristics. Still, Li Xuehong (2005) held that the fossilization of thinking pattern and insufficient competence both in Chinese and English can also result in Chinglish. Although there has been no consensus on the causes of Chinglish so far, it is commonly agreed that Chinglish is an objective reality and requires special attention in the academic field.

\section{English Scientific Journals in China}

Apart from the Chinese journals edited by universities enlisted in the national "985 Project", there are usually English scientific journals which are published toward both Chinese and foreign readers. However, many of the theses carried by those English journals are authored by Chinese scholars and most of them are often not written directly in English but are translated into English from their Chinese texts.

It has been found in the mini corpus data that Chinglish is widespread in many theses of English scientific journals published in China. The English contents tend to rigidly abide by their Chinese words, sentences or discourses. The authors usually seek to reach a mechanical equivalence which, in fact, leads to redundant phrases or unclear passages, hence impairing the preciseness and rigorousness characterizing scientific thesis.

\section{Chinglish at the Lexical Level}

An obvious characteristic of Chinglish at the lexical level is that many redundant words can be found in the college English scientific journals in China because of the interference of Chinese thinking pattern and expressing conventions. Such redundancy consists of redundant nouns, verbs and modifiers.

Firstly, redundant nouns are used to fulfil repeated references or pile up similar meanings. For instance: (Italicized words are marked out for note.)

1) The coverage problem is a fundamental problem in WSNs for environment monitoring and surveillance purposes. (Cheng Caixia, 2011)

2) The attention area in a picture is the area which tends to catch more human visual attention. (Wang Xiaolong, 2011)

3) Two existing fusion operators, including the cumulative fusion operator and the averaging fusion operator, are used to fuse independent opinion and dependent opinion respectively. (Zhou Hongwei, 2011)

4) Liquid helium is filled from the liquid helium tank into the transfer dewar and then from the transfer dewar into the master dewar. (Yang Yupu, 2011)

5) The main alloys used for plasma spray and plasma spray welding were Nickel-based self-fluxing alloy and cobalt-based self-fluxing alloy. (Zen Zhiqiang, 2012)

In the above 5 examples, the authors are obviously confined by the Chinese words and most of the italicized words are unnecessarily repeated. Joan Pinkham (2004) thought that one of the typical features of Chinglish is "noun plague". In the first example, "problem" in Chinese is a category word and can be eliminated. Similar words like "phenomenon", "situation" or "state" can also be redundant for they usually represent nothing meaningful in the Chinese context. Besides, "for" and "purposes" are repeating similar meanings. Meanwhile, the same nouns are overly repeated in each example, and it can be safely said that negative transfer of Chinese causes such redundancy. Brevity is the soul of wit. Therefore, all the examples fail to abide by the standard of being brief and being accurate for scientific thesis. 
Secondly, redundant verbs are often characterized by the typical Chinglish verbal collocation "unnecessary verb + noun”. Such collocation can easily found with verbs like "make", "do", "have" and "take", etc. The verb "make" is examined through MicroConcord and data in relation to it are collected in table 1 as follows:

\begin{tabular}{|c|c|c|}
\hline $\begin{array}{r}\text { only need to } \\
\text { a model and } \\
\text { in order to } \\
\text { different paths to }\end{array}$ & $\begin{array}{l}\text { make } \\
\text { make } \\
\text { make } \\
\text { make }\end{array}$ & $\begin{array}{l}\text { adjustments according to } \\
\text { an assumption of } \\
\text { the comparison of } \\
\text { the best utilization }\end{array}$ \\
\hline of active. We & make & $\begin{array}{ll}\text { the } & \text { following } \\
\text { assumptions } & \end{array}$ \\
\hline and risk should & make & $\begin{array}{l}\text { effective selections } \\
\text { before }\end{array}$ \\
\hline $\begin{array}{l}\text { workshop, and to } \\
\text { control variables to }\end{array}$ & $\begin{array}{l}\text { make } \\
\text { make }\end{array}$ & $\begin{array}{l}\text { our observations along } \\
\text { optimal decision with }\end{array}$ \\
\hline an attacker to & make & $\begin{array}{l}\text { malicious behaviors, } \\
\text { such }\end{array}$ \\
\hline
\end{tabular}

It can clearly be seen that all the "make + noun" collocation in table 1 can readily be replaced by their corresponding verbs like "adjust”, “assume”, “compare”, "utilize”, “select”, “observe”, "decide", and "behave". Further, other similar collocations are very common in Chinglish and Chinese authors tend to use them in English scientific writing. Joan Pinkham (2004) held that Chinglish is a language based on general and vague nouns while English is based on vigorous and concise verbs. The former is usually complicated, longwinded, ponderous and obscure; the latter is usually simple and clear.

Thirdly, Chinese authors tend to overuse redundant modifiers which are very common in Chinese. Modifiers usually refer to the adverbs which are used to either strengthen or weaken the word they accompany. "Quite", "relatively", and "rather" are commonly used and their Chinese equivalents can be frequently seen in academic writings. As for "quite" and "relatively", the Chinese equivalents often sound not so objective or subjective, reflecting the typical Chinese way of not making absolute statements so that the Chinese writer or speaker will not be unfavorably judged in the Chinese context. Therefore, the same happens when Chinese scholars write English thesis just as is shown in the following table.

Table 2 unnecessary modifier "relatively"

\begin{tabular}{rll}
\hline calcite, which yield & relatively & darker BSE images \\
DMU could be & relatively & efficient but not \\
of DNA is & relatively & easy to be \\
bacteria reached a & relatively & high density. As \\
and Al with & relatively & higher content are \\
concrete structures, a & relatively & intact zone on \\
will take a & relatively & longer time for \\
anodic films is & relatively & highest and X-ray \\
deviations are both & relatively & large, and with \\
\hline
\end{tabular}

It is all very well to use modifiers occasionally in English scientific writing if authors do not want to make their statements or conclusions sound too direct to be reliable. However, overuse of these modifiers can give the readers such impression that the intended meaning is actually unclear or the author is lacking in self-confidence. Readers may even think that the author is unable or unwilling to clearly express his or her attitude.

\section{Chinglish at the Syntax Level}

Chinese and English belong to different family of languages and the two consequently have distinct syntactical features respectively. Both Wang Li (1982) and Eugen Nida (1984) believed that 
Chinese is characterized by parataxis and English hypotaxis. Parataxis means that Chinese highlights the topic with omitted subject on many occasions and sentences are usually connected through contextual coherence. Chinese thus has an implicit syntactical structure. Hypotaxis, on the other hand, indicates that English features a prominent structure of subject and predicate and English sentences usually need connectives to get combined with each other. Therefore, English has an explicit syntactical structure. As parataxis and hypotaxis are totally different, it is natural for Chinese scholars to write English sentences characterized by Chinglish. For instance: (Italicized words are marked out for note.)

The alert system, developed in JAVA, is running all the time the web server is running. This alert system is in charge of the LiveWeb notification service. To realize real-time service, off-line notification is critical. The alert system is based on an efficient subscription/alert mechanism and various communication methods. LiveWeb treats the new item included in a user's criteria as an event. The alert system sends the event notification to the users automatically. (Yang Xiaogang, 2011)

The above passage is typically written in Chinglish. It consists of 6 short sentences among which 4 of them have repeated the same subject “alert system". There are also no connectives among the 6 sentences, reflecting the Chinese scattering thinking pattern. Although the whole passage is written in English, it has a very strong paratactic feature. If such a passage is indeed a translated text, the translator is also supposed not to strictly follow the original cohesion because at least he/she must consider the differences of language and thinking mode and amplify the target language text in a necessary way. In other words, connectives need to be added so that the implicit Chinese syntactical structure can be explicitly reproduced, making the translation text and original passage agree with each other in content and structure if it is feasible.

\section{Suggestions on Eliminating Chinglish}

Most of the college English scientific journals in China are intended to move toward a wider academic world and be recognized by foreign readers. However, Chinglish in those journals weakens their academic quality and hinders them from attaining their publication aims. It is therefore an urgent issue to have the Chinglish eliminated.

First and foremost, English competence must be improved. Chinese scholars shall endeavor to become proficient in English so that they can have a better chance of shaking off the native transfer caused by the Chinese language and Chinese thinking mode. They must often read the scientific literatures written by those English-speaking scholars. As for the editors of the English scientific journals, they are also supposed to enhance their English competence so that they can correct the Chinglish in time. Editors shall also uphold the principle as is stipulated in American Engineering Index (EI) that English theses must be complete, clear and concise.

Secondly, English-speaking editors shall be included in examining the contributed theses by Chinese scholars. Zhou Yu and Wang Yimin (2005) pointed out that only a small part of the top universities like Tsinghua University, Peking University and Fudan University have already set up an international editing board for the contributions. In the meaning time, presses of college English scientific journals shall follow the example of the Nature, Science, Cell and other internationally renowned journals so that they can draw on them to standardize the theses contributed by Chinese scholars, hence guaranteeing the academic quality.

Thirdly, contributions to the college English scientific journals in China must be expanded to include more foreign authors. International contributions demand that authors have higher English competence not only in thesis structure but also in its content and drawing excellent international contributors will help to increase the impact factors of the theses as well as journals. Consequently, domestic contributors will undoubtedly be spurred on to learn from their international counterparts and try to improve their scientific English writing so that less Chinglish will appear in their theses. 


\section{References}

[1] Oldin, T. Language Transfer. Cambridge: Cambridge University Press, 1989.

[2] W.Z. Li. China English and Chinglish. Foreign Language Teaching and Research, 1993, 36(4):18-24.

[3] J.Z. Zhuang. On Chinglish. Chinese Translator Journal, 2000, 21(6):7-10.

[4] N.S. Wang. Chinglish in C-E Translation. Chinese Translator Journal, 2000, 21(2):31-35.

[5] X.H. Li. On the Causes of Chinglish. Journal of Hefei University of Technology, 2005, 19(4):119-123.

[6] Caixia, Cheng et al. One Fire Detection Method Using Neural Networks.Tsinghua Science and Technology, 2011, 16(1):31-35.

[7] X.L. Wang et al. Attention-based Adaptive Intra Refresh Method for Robust Video Coding.Tsinghua Science and Technology, 2011, 16(4):491-504.

[8] H.W. Zhou et al. Using New Fusion Operations to Improve Trust Expressiveness of Subjective Logic. Wuhan University Journal of Natural Sciences, 2011, 16(5):376-382.

[9] Y.P. Yang et al. Control System Design and Test for Cryogenic Ground Support Equipment. Journal of Shanghai Jiaotong University, 2011, 16(5):543-550.

[10] Z.Q. Zeng et al. Preparation of Ni60-Cr3C2 Coating by Plasma Spraying, Plasma Re-melting and Plasma Spray Welding. Journal of Wuhan University of Technology, 2012, 18(2):389-393.

[11] Pinkham, Joan. The Translator's Guide to Chinglish. Beijing: Foreign Language Teaching and Research Press, 2000.

[12] L. Wang. Theory of Chinese Grammar. Jinan: Shandong Education Press, 1984.

[13] Nida, E. A. Translating Meaning. San Dimas, California: English Language Institute. 1982.

[14] X.G. Yang et al. LiveWeb: A Sensorweb Portal for Sensing the World in Real-time.Tsinghua Science and Technology, 2011, 16(5): 491-504.

[15] Y. Zhou, Y.M. Wang. International Trend of Scientific Journals in China. Acta Editologica, 2005, 17(1):13-14. 